\title{
Ten-Year Experience with Open Prostatectomy in Maiduguri
}

\author{
Ibrahim Ahmed Gadam, ${ }^{1,2}$ Ali Nuhu, ${ }^{1,2}$ and Suleiman Aliyu ${ }^{1,2}$ \\ ${ }^{1}$ Department of Surgery, University of Maiduguri Teaching Hospital, PMB 1414, Borno State, Maiduguri, Nigeria \\ ${ }^{2}$ Department of Surgery, College of Medical Sciences, University of Maiduguri, Nigeria
}

Correspondence should be addressed to Ali Nuhu, nuhualinvwa@yahoo.com

Received 11 August 2012; Accepted 21 October 2012

Academic Editors: A. Fandella, A. C. Thorpe, and K. H. Tsui

Copyright (C) 2012 Ibrahim Ahmed Gadam et al. This is an open access article distributed under the Creative Commons Attribution License, which permits unrestricted use, distribution, and reproduction in any medium, provided the original work is properly cited.

\begin{abstract}
Background. Benign prostatic hyperplasia is the most common cause of lower urinary tract obstruction in the elderly male. Aim. To evaluate the effectiveness, safety, and outcome of open prostatectomy in a Nigerian teaching hospital. Material and Methods. Two hundred and fifty-three men with lower urinary tract obstruction clinically due to benign prostatic hyperplasia (BPH) underwent open prostatectomy over a ten-year period (January 2001-December 2010). Data on patients including age, clinical, laboratory, and histology were reviewed and analyzed to determine treatment outcome. Results. A total of 253 patients were studied. Their mean age was $69.11 \pm 10.9$ years (range 50-98). The most common symptoms at presentation included frequency $229(90.5 \%)$ and poor stream 225 (88.9\%). The most common complications at presentation were stones in 41 (16.2\%) and bleeding in $37(14.6 \%)$. The most common comorbid conditions were hypertension and diabetes found in $72(28.5 \%)$ and $23(9.1 \%)$, respectively. Transvesical prostatectomy was done for most of the patients, $126(49.8 \%)$. Clot retention and wound infection were the commonest postoperative complications accounting for $19(7.5 \%)$ each. Transient incontinence occurred in 17 $(6.7 \%)$ patients. There was $1(0.4 \%)$ mortality. Conclusion. Open prostatectomy still has a prime place in the operative treatment of BPH with acceptable postoperative morbidity and very low mortality in the developing world with no facilities for TURP.
\end{abstract}

\section{Introduction}

Open prostatectomy has been the operative treatment for benign prostatic enlargement for several decades until the advent of transurethral resection of the prostate TURP (the gold standard) [1] and other state-of-the act modalities like transurethral interstitial LASER ablation [2], thermotherapy [3], and needle ablation [4]. This led to the gradual reduction in open prostatectomy in the developed world. In the developing countries, however, skills in traditional open surgery are mandatory, because the patients present late with very large prostates. A gland that is too large and completely obscuring the trigone and the ureteric orifices will not be comfortably resected transurethrally. Most urologists are comfortable with removing glands in the range of $50-75 \mathrm{~g}$, transurethrally open surgery is, therefore, recommended for larger glands [5]. Comorbid medical conditions and complications of $\mathrm{BPH}$ at presentation are also indications for open prostatectomy [6]. The aim of this study was to review our ten-year experience with open prostatectomy, with special emphasis on the challenges of late presentation, complications of lower urinary tract obstruction, and comorbid medical conditions.

\section{Patients and Methods}

All patients who underwent open prostatectomy for BPH at the UMTH between January 2001 and December 2010 were retrospectively reviewed. Details of their biodata, clinical presentation, diagnostic investigations, operative treatment (Table 5), histological reports, postoperative complications, and other outcomes of surgery were extracted from their hospital records and analyzed. The diagnosis of BPH was made on clinical assessment, which included digital rectal examination and abdominopelvic ultrasound scan additional tests like PSA level and prostatic biopsy were reserved for suspicion of malignancy and when confirmed were excluded from the study. Open prostatectomy was performed on all the patients after resuscitation and initial urethral 
TABle 1: Age distribution.

\begin{tabular}{lc}
\hline Age $(\mathrm{yrs})$ & Number $(\%)$ \\
\hline $50-59$ & $52(20.6)$ \\
$60-69$ & $72(28.5)$ \\
$70-79$ & $76(30.0)$ \\
$80-89$ & $39(15.4)$ \\
$>90$ & $14(5.5)$ \\
\hline Total & $253(100)$ \\
\hline
\end{tabular}

TABle 2: Symptoms at presentation.

\begin{tabular}{lc}
\hline Symptoms & Number $(\%)$ \\
\hline Frequency & $229(90.5)$ \\
Poor stream & $225(88.9)$ \\
Difficulty in passing urine & $142(56.1)$ \\
Acute urinary retention & $124(49.0)$ \\
Urgency/urge incontinence & $116(45.3)$ \\
Nocturia & $109(43.1)$ \\
Hesitancy & $93(36.8)$ \\
Incomplete emptying of bladder & $80(31.6)$ \\
Postmicturition dribbling & $60(23.7)$ \\
Haematuria & $30(11.9)$ \\
Incontinence & $6(2.4)$ \\
\hline
\end{tabular}

catheterization for continuous drainage where necessary, ensuring optimal renal function and treating any urinary tract infection with antibiotics based on sensitivity. Preoperative blood transfusion was given for bleeding prostates that came with anaemia. Methods of prostatectomy included transvesical, transcervical (low transvesical), and retropubic ones based on complications at presentation and surgeon's discretion. In low transvesical (transcervical) one, the incision is placed transversely across the bladder neck.

\section{Results}

This is a ten-year (January 2001-December 2010) retrospective review of open prostatectomy in 253 patients that had benign prostatic hyperplasia (BPH).

Table 1 depicts the age distribution of the patients. The mean age was $69.1 \pm 10.9$ years (range 50-98). The 70-79year age group accounted for the highest number of patients (76), that is, $30.0 \%$.

The main symptoms at presentation as seen in Table 2 are frequency of micturition in $229(90.5 \%)$ patients, poor urinary stream $225(88.9 \%)$, and difficulty in passing urine $142(56.1 \%)$. The mean duration of symptoms was $25.8 \pm$ 27.5 months (range 1-168 months). All the patients had enlarged prostate with grossly benign features on digital rectal examination and abdominopelvic ultrasound scan. The complications at presentation (Table 3 ) included urinary tract stones in $41(16.2 \%)$, groin hernia in $38(15.0 \%)$; the least complication at presentation was impaired renal function in $18(7.1 \%)$ patients. Vaginal hydrocele was an incidental finding in $12(4.7 \%)$ of the patients.
TABLE 3: Complications at presentation.

\begin{tabular}{lc}
\hline Complications & Frequency (\%) \\
\hline Stones & $41(16.2)$ \\
Hernias & $38(15.0)$ \\
Bleeding & $37(14.6)$ \\
Urinary tract infection & $27(10.7)$ \\
Hydronephrosis/hydroureters & $21(8.3)$ \\
Haemorrhoids & $20(7.9)$ \\
Renal impairment & $18(7.1)$ \\
Hydrocele (incidental finding) & $12(4.7)$ \\
\hline
\end{tabular}

TABLE 4: Intraoperative findings.

\begin{tabular}{lc}
\hline Intraoperative findings & Frequency $(\%)$ \\
\hline (a) Bladder & \\
Thickened wall & $119(47.0)$ \\
Diverticuli & $26(10.3)$ \\
Trabeculations/sacculations & $39(15.4)$ \\
Stones & $35(13.8)$ \\
(b) Prostate & \\
Median lobe enlargement & $36(14.2)$ \\
Global enlargement & $202(79.8)$ \\
Fibrotic prostate & $6(2.4)$ \\
\hline
\end{tabular}

TABLe 5: Operative technique.

\begin{tabular}{lc}
\hline Operative technique & Frequency $(\%)$ \\
\hline Transvesical & $126(49.8)$ \\
Low transvesical & $23(9.1)$ \\
Retropubic & $104(41.1)$ \\
\hline Total & $253(100)$ \\
\hline
\end{tabular}

A total of $38(15 \%)$ patients were anaemic at presentation (i.e., PCV less than 30\%). The urine culture was positive for bacteria in 135 (53.4\%). This warranted antibiotic therapy in these patients. Clinically significant electrolyte derangement (renal impairment) was seen in 18 (7.1\%). The premorbid conditions in the patients included hypertension in $72(28.5 \%)$, diabetes $23(9.1 \%)$, arthritis $17(6.7 \%)$, and Parkinson's disease in $11(4.3 \%)$ of the patients; lumbar spondylosis was seen in $9(3.6 \%)$. Dementia $4(1.6 \%)$ and $4(1.6 \%)$ patients had various allergies while epilepsy was seen in $4(1.6 \%)$ and HIV $5(1.9 \%)$. Three $(1.2 \%)$ were blind and $2(0.8 \%)$ were deaf. Most of the patients had open prostatectomy under spinal anaesthesia 208 (82.2\%), whereas general anaesthesia was used in $45(17.8 \%)$ patients. Transvesical prostatectomy was done for most of the patients and accounted for 126 (49.8\%), followed by retropubic in $104(41.1 \%)$. Low transvesical was another method in 23 (9.1\%).

Intraoperative findings were particularly for the prostate itself and the gross appearance of the bladder as depicted in Table 4. Majority of the patients 119 (47.0\%) had bladder wall hypertrophy, while trabeculations and sacculation of the bladder were seen in $39(15.4 \%)$. Diverticuli and 
TABLe 6: Postoperative complications.

\begin{tabular}{lc}
\hline Complications & Frequency $(\%)$ \\
\hline Retrograde ejaculation & $20(7.9)$ \\
Clot retention & $19(7.5)$ \\
Wound infection & $19(7.5)$ \\
Incontinence of urine & $17(6.7)$ \\
Erectile dysfunction & $17(6.7)$ \\
Urinary tract infection & $14(5.5)$ \\
Vesicocutaneous fistula & $13(5.1)$ \\
Others & $27(10.7)$ \\
\hline
\end{tabular}

Others:

Epididymoorchitis $=8$, cardiac failure $=2$, and renal failure $=1$.

Bladder neck stenosis/stricture $=5$.

Irritable bladder syndrome $=5$.

Pneumonia/atelectasis $=4$.

Deep vein thrombosis $=2$.

bladder stones were seen in $26(10.3 \%)$ and $35(13.8 \%)$, respectively. The prostate was seen to have an isolated median lobe enlargement in $36(14.2 \%)$ of the patients, global enlargement in $202(79.8 \%)$, while $6(2.4 \%)$ were found to be fibrotic. The mean estimated blood loss was $110 \mathrm{mls}$ (85$238 \mathrm{mls}$ ).

The postoperative complications (Table 6) included retrograde ejaculation in 20 (7.9\%); clot retention and wound infection were seen in $19(7.5 \%)$ each. The least postoperative complication was renal failure seen in $1(0.4 \%)$ patient.

The mean weight of the prostate was $103.6 \pm 67.0$ (range 36-426 g). The histology of removed prostates showed benign features (BPH) in 239 (94.5\%) and malignant foci in background benign hyperplasia (incidental carcinoma) in 14 (5.5\%) of patients.

\section{Discussion}

Until 20-25 years ago, open surgery was the most common approach to the prostate in benign prostatic hyperplasia. From the late 1970s, however, the development of endoscopes led to a gradual reduction in the number of open surgical operations for the prostate, and open prostatectomy continued to decrease rapidly in favor of the minimally invasive endoscopic techniques. Therefore, open surgery for BPH is declining though still performed. Skills in traditional open surgery are still the main approach and are in fact mandatory in most developing countries who cannot afford widespread use of minimally invasive techniques of prostatectomy. Open surgery is still important to all surgeons because indications for it still exist.

Two hundred and fifty-three patients, who had open prostatectomy for $\mathrm{BPH}$, were reviewed indicating their clinical presentation, associated comorbid medical conditions, and management outcome. The mean age of 69.11 years is not different from other studies [7]. The clinical features of $\mathrm{BPH}$ are the same with other studies; however the complications at presentation are in sharp contrast to what is obtainable in developed countries $[6,8]$ where recurrent urinary retention predominates. Haemorrhage, very huge prostates, associated with diverticuli, bladder stones, and impaired renal function which are all features of late presentation are common in the developing countries $[9,10]$. In addition to late presentation is the prevalence of comorbid medical conditions like hypertension and diabetics. The combination of the above factors is a major indication for open surgery, even where there are facilities for modern minimal access techniques. Massive persistent haemorrhage in BPH is a fairly common and life-threatening complication at presentation in this study; there were $37(14.6 \%)$, lower than that reported by Ramyil et al. [11]. These patients were managed by emergency transvesical prostatectomy, which is a safe procedure that allows for direct control of haemorrhage. Other methods employed in dealing with bleeding prostates include continuous bladder irrigation, bladder instillations, and selective arterial prostatic embolization $[12,13]$.

Diverticuli, bladder stones, and hernias are common complications associated with lower urinary tract obstruction. These were dealt with during prostatectomy, the same primary surgery. Obstructive lower urinary tract symptoms complicated by impaired renal function evidenced by elevated creatinine are known to improve or return to normal after variable periods of continuous urethral catheter drainage. This was our experience in most of our patients who improved within 7 to 14 days.

Comorbid medical conditions are common among this group of elderly males. This leads to an increased incidence of complications during or after prostatectomy; therefore, a prudent care is required to make them safe for surgery [6]. In this study, the most common comorbid medical conditions were diabetes and hypertension, which is similar to other studies [14].

Open prostatectomy is still safe though with longer hospital stay than minimally invasive techniques [15].

In this series, the mean weight of removed prostates was $103.6 \pm 67.0$ with a range of $36-426 \mathrm{~g}$; this is far more than the weight recommended by EAU Guidelines for open prostatectomy which is between 80 and $100 \mathrm{~g}$ [16]. This is still a problem of late presentation in the developing countries. Open prostatectomy is accepted as the treatment of choice for large glands $(>80-100 \mathrm{~g})$. Three recent randomized controlled trials (RCTs) have shown that Holmium laser enucleation and PVP (transurethral photoselective vaporization of the prostate) have comparable outcomes to open prostatectomies in men with glands between 70 and $100 \mathrm{mls}$ [17]. This underscores the fact that open prostatectomy though the most invasive is still the most effective and durable treatment.

Clot retention and wound infection were the major postoperative complications in this series comparable to similar studies $[15,18]$. Transient incontinence, a wellknown complication especially in transvesical prostatectomy, was comparable to other similar series $[15,18]$; however, the incidence of retrograde ejaculation was low. This may be attributed to the cultural barrier or inhibition of volunteering such information [19]. The low mortality rate of $0.4 \%$ is in keeping with current trend of decreasing mortality from major urological procedures [20]. The one patient that died $(0.4 \%)$ was as a result of pulmonary embolism 
following deep vein thrombosis, which is not an uncommon complication of major pelvic surgeries [21].

\section{Conclusion}

Open prostatectomy with its attendant lower mortality and morbidity is still necessary in the operative management of benign prostatic hyperplasia. Open procedures for $\mathrm{BPH}$ are still necessary for huge, bleeding, and complicated prostates despite the advent of modern minimally invasive techniques. For safe surgery and avoidance of postoperative complications, comorbid medical conditions associated with advancing age must be addressed.

\section{Conflict of Interests}

The authors declare that they have no conflict of interests.

\section{References}

[1] R. Hartung, "Transurethral prostatectomy (TURP): still the gold standard?" Journal d'Urologie, vol. 101, no. 1, pp. 18-21, 1995.

[2] Y. Arai, S. Ishitoya, K. Okubo, and Y. Suzuki, “Transurethral interstitial laser coagulation for benign prostatic hyperplasia: treatment outcome and quality of life," British Journal of Urology, vol. 78, no. 1, pp. 93-98, 1996.

[3] M. A. Cabelin, A. E. Te, and S. A. Kaplan, "Transurethral vaporization of the prostate: current techniques," Current urology reports, vol. 1, no. 2, pp. 116-123, 2000.

[4] M. J. Naslund, "The cost comparison TUNA versus TURP," Journal of Urology, vol. 157, p. 155, 1997.

[5] R. Sood, V. Jain, and D. Chauhan, "Giant prostatic hyperplasia: surgical management of a case," Journal of Postgraduate Medicine, vol. 52, no. 3, pp. 232-233, 2006.

[6] K. Kurokawa, Y. Tamura, H. Ogura et al., "Open surgery of elderly patients with benign prostatic hypertrophy," Acta Urologica Japonica, vol. 36, no. 10, pp. 1167-1172, 1990.

[7] N. A. Berhanu, "Safety and efficacy of transversical prostatectomy done at primary general hospital setting in Ethiopia," East and Central African Journal of Surgery, vol. 13, pp. 53-60, 2008.

[8] A. Tubaro, S. Carter, A. Hind, C. Vicentini, and L. Miano, "A prospective study of the safety and efficacy of suprapubic transvesical prostatectomy in patients with benign prostatic hyperplasia," Journal of Urology, vol. 166, no. 1, pp. 172-176, 2001.

[9] E. E. Akpo and M. O. Akpo, "Giant benign prostatic hyperplasia in a Nigeria: report of a case," The Internet Journal of Urology, vol. 8, no. 1, 2011.

[10] H. Yonou, M. Goya, M. Miyazato, K. Sugaya, T. Hatano, and Y. Ogawa, "Giant prostatic hypertrophy: a case report," Hinyokika Kiyo, vol. 45, no. 5, pp. 375-377, 1999.

[11] V. M. Ramyil, N. K. Dakum, H. U. Liman, and E. I. Udeh, "The management of prostatic haematuria," Nigerian Journal of Medicine, vol. 17, no. 4, pp. 439-442, 2008.

[12] E. B. Ostroff and O. W. Chenault, "Alum irrigation for the control of massive bladder hemorrhage," Journal of Urology, vol. 128, no. 5, pp. 929-930, 1982.

[13] N. V. Raghavaiah and M. S. Soloway, "Anuria following silver nitrate irrigation for intractable bladder hemorrhage," Journal of Urology, vol. 118, no. 4, pp. 681-682, 1977.
[14] J. Concato, R. I. Horwitz, A. R. Feinstein, J. G. Elmore, and S. F. Schiff, "Problems of comorbidity in mortality after prostatectomy," Journal of the American Medical Association, vol. 267, no. 8, pp. 1077-1082, 1992.

[15] D. K. Kiptoon, G. A. O. Magoha, and F. A. Owillah, "Early postoperative outcomes of patients undergoing prostatectomy for benign prostatic hyperplasia at Kenyatta National Hospital, Nairobi," East African Medical Journal, vol. 84, no. 9, supplement, pp. S40-S44, 2007.

[16] V. Serretta, G. Morgia, L. Fondacaro et al., "Open prostatectomy for benign prostatic enlargement in southern Europe in the late 1990s: a contemporary series of 1800 interventions," Urology, vol. 60, no. 4, pp. 623-627, 2002.

[17] R. M. Kuntz, K. Lehrich, and S. A. Ahyai, "Holmium laser enucleation of the prostate versus open prostatectomy for prostates greater than 100 grams: 5-year follow-up results of a randomised clinical trial," European Urology, vol. 53, no. 1, pp. 160-168, 2008.

[18] A. G. Hill and P. Njoroge, "Suprapubic transvesical prostatectomy in a rural Kenyan hospital," East African Medical Journal, vol. 79, no. 2, pp. 65-67, 2002.

[19] A. Gregoire, "ABC of sexual health: assessing and managing male sexual problems," British Medical Journal, vol. 318, no. 7179, pp. 315-317, 1999.

[20] I. Varkarakis, Z. Kyriakakis, A. Delis, V. Protogerou, and C. Deliveliotis, "Long-term results of open transvesical prostatectomy from a contemporary series of patients," Urology, vol. 64, no. 2, pp. 306-310, 2004.

[21] H. Hendolin, M. A. K. Mattila, and E. Poikolainen, "The effect of lumbar epidural analgesia on the development of deep vein thrombosis of the legs after open prostatectomy," Acta Chirurgica Scandinavica, vol. 147, no. 6, pp. 425-429, 1981. 


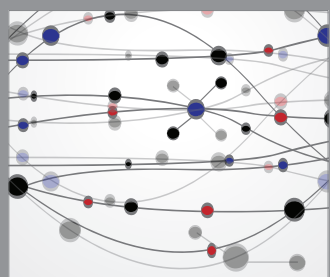

The Scientific World Journal
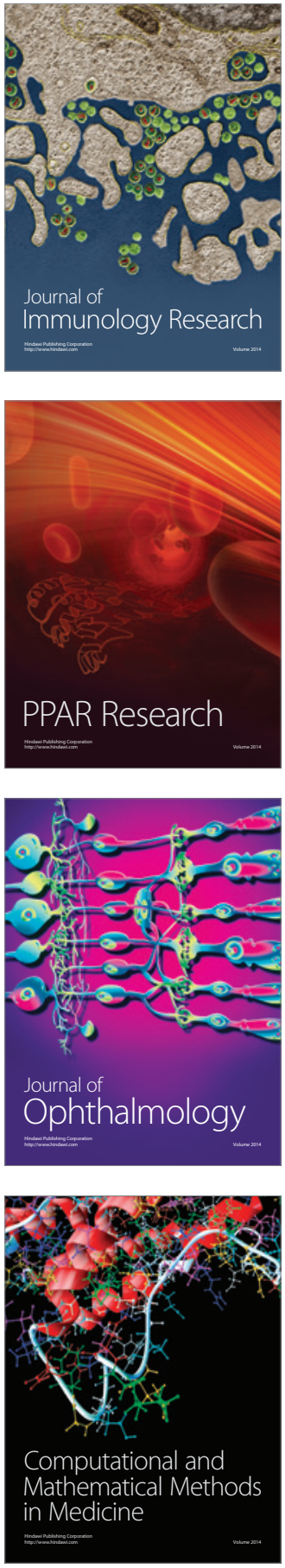

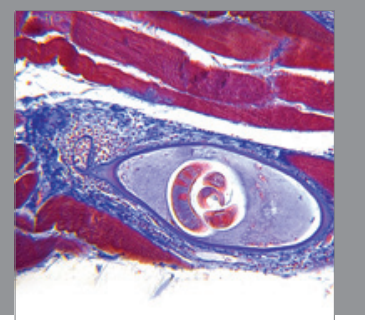

Gastroenterology

Research and Practice
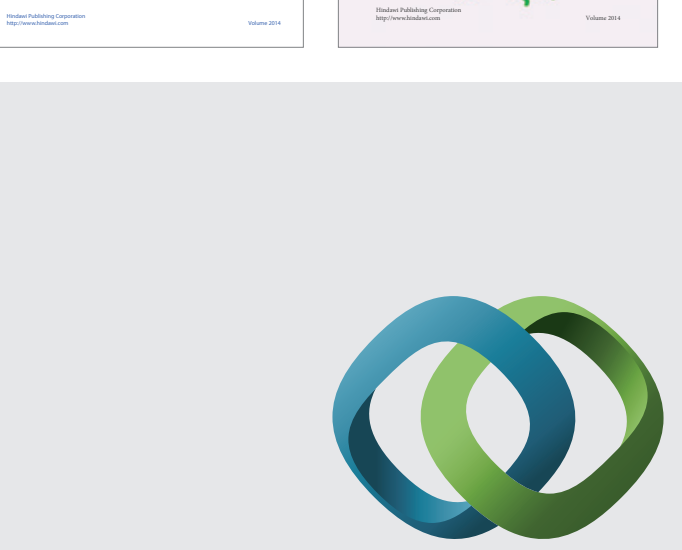

\section{Hindawi}

Submit your manuscripts at

http://www.hindawi.com
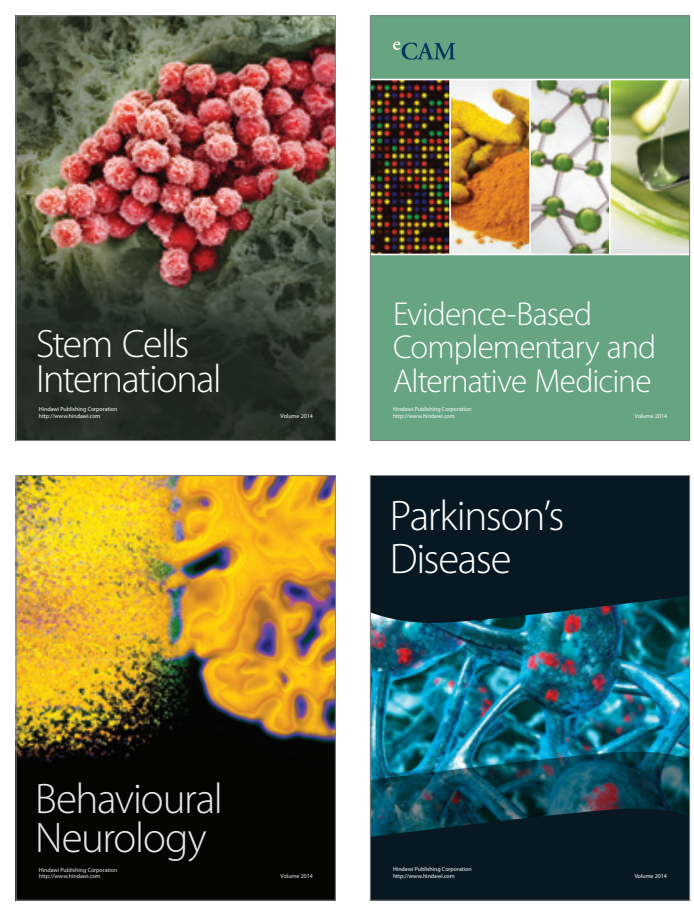

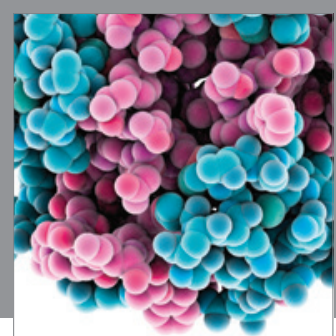

Journal of
Diabetes Research

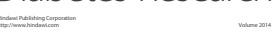

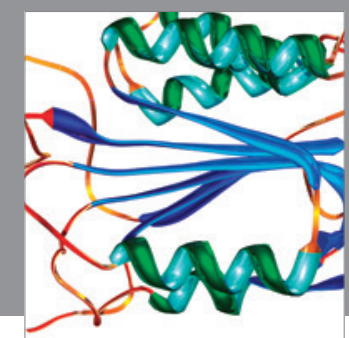

Disease Markers
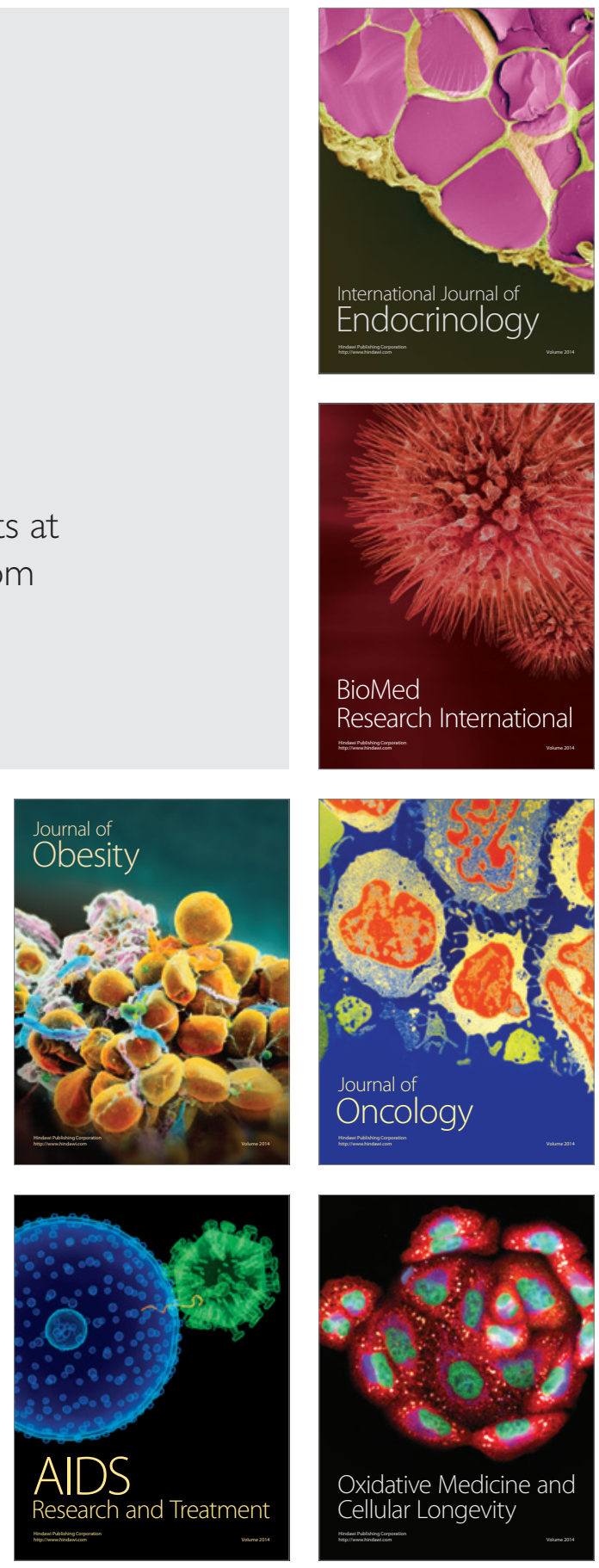